\title{
RANCANG BANGUN APLIKASI RESEP MASAKAN BERBASIS ANDROID
}

\author{
Supriyanto \\ Teknik komputer \\ STMIK Dian Cipta Cendikia Kotabumi \\ Email: Supriyanto@dcc.ac.id
}

\begin{abstract}
ABSTRAK
Perkembangan Teknologi dan Informasi yang semakin cepat saat ini terutama untuk sebuah informasi, Sebagai salah satu produk dari perkembangan ilmu dan teknologi, komputer sering digunakan baik sebagai alat penelitian maupun alat pengolahan data dan pengembangan sistem.
\end{abstract}

Metode Pengembangan Sistem yang digunakan oleh peneliti dalam penelitian ini adalah metode pengembangan sistem Prototype dengan konsep use case. Use case adalah deskripsi dari sebuah perilaku sistem sebagai respon dari suatu aksi / permintaan dari luar sistem

Peneliti membuat perancangan sistem informasi resep masakan berbasis mobile/android, dan proses pencarian resep masakan tidak lagi menggunakan buku resep atau sejenisnya karena sudah menggunakan aplikasi yang ada dalam smartphone android,

Kata kunci : Aplikasi Mobile, Resep Masakan Berbasis Android, Metode Prototype, Php, Mysql, Bootstrap, W3S, Appsgeyser.

\section{ABSTRACT}

The development of technology and information is increasingly fast now, especially for information. As a product of the development of science and technology, computers are often used both as research tools and as data processing and system development tools.

The System Development Method used by researchers in this study is the method of developing the Prototype system with the use case concept. Use case is a description of a system behavior in response to an action / request from outside the system

The researcher designed a mobile / android based recipe information system. the search process for recipes is no longer using recipe books or the like because they already use an application in an android smartphone Keywords: Mobile Applications, Android Based Recipes, Prototype Methods, Php, Mysql, Bootstrap, W3S, Appsgeyser 


\section{PENDAHULUAN}

Perkembangan teknologi dari tahun ketahun sangat pesat dan akan terus semakin berkembang dari hari ke hari, terutama dibidang Informasi [1]. Baik itu informasi dari media cetak maupun elektronik yang menyajikan informasi dalam bentuk tulisan, suara maupun gambar.

Dengan mengunakan media untuk mendapatkan iformasi makanan dan sekaligus sebagai acuan untuk menyalurkan hobi memasak tersebut. Dengan adanya perancangan aplikasi mobile yang akan di buat dan dengan aplikasi yang diharapkan dapat bisa membantu untuk mendapatkan informasi berupa resep-resep masakan khas Indonesia yang juga disertai dengan berbagai tips-tips memasak dari database berdasarkan kategori yang dibutuhkan oleh pengguna. Maka semua resep makanan yang kita inginkan dapat kita lihat langsung hanya memalui smartphone Android.

Dalam penelitian sebelumnya dengan memanfaatka teknologi komputer dan online seperti pada penentuan letak, rute kendaraan bis trans lampung [2]. Dalam penelitian sebelumnya juga [3][5] menjelaskan bahwa dalam memebuat aplikasi online penulis menggunakan Aplikasi pemesanan untuk pelanggan terdiri dari Delivery Service, Paket Catering Service, dan Paket Catering Ruang Minang. Sedangkan aplikasi untuk admin terdiri dari olah data menu utama, transaksi, dan laporan. Untuk transaksi pembayaran dilakukan secara cash kepada bagian pengiriman. Sistem aplikasi ini dibangun dengan menggunakan PHP dan database MySQL. hasil diskusi/pemikiran harus memuat PENDAHULUAN;

PEMBAHASAN;

KESIMPULAN; dan DAFTAR PUSTAKA (dengan jumlah jurnal minimal yang diacu 10). Abstrak ditulis dalam bahasa Indonesia dan bahasa Inggris serta dilengkapi dengan kata kunci (keywords).

\section{METODOLOGI PENELITIAN}

\subsection{Teknik Pengumpulan Data}

Pengumpulan data yang dilakukan dalam penelitian ini adalah melalui proses wawancara . studi pustaka dan observasi .

\subsection{Metode pengembangan sistem}

Dalam penelitian sebelumnya , [4] memanfaatkan alat penengenbangan sistem UML dalam upaya untuk pengembangan prototyping, dalam penelitian ini penulis menggunakan metode pengembangan prototyping, yang dalam prosesnya sangat sesuai dengan aplikasi yang akan dibuat ,

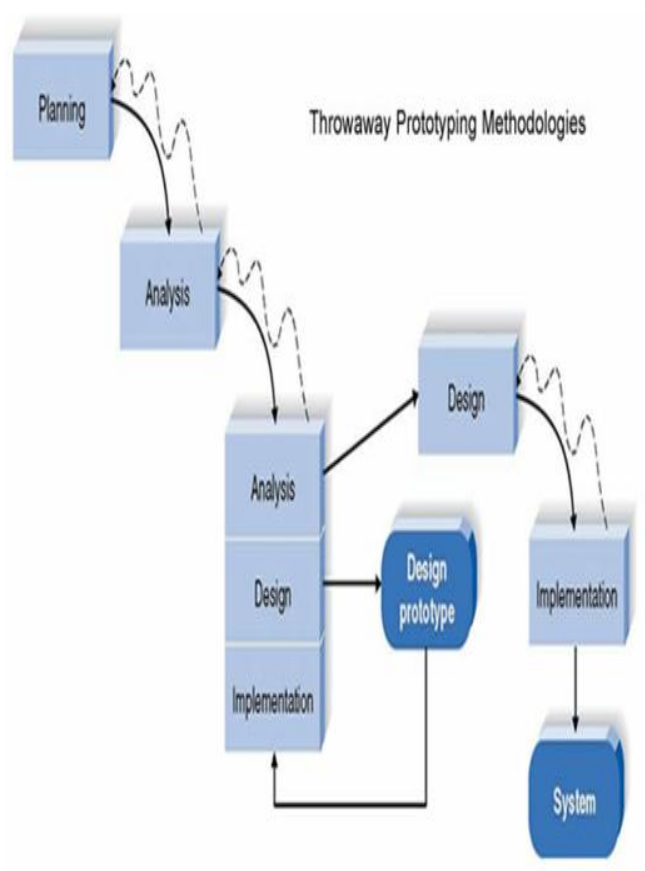

Gambar 1 Metode Prototype 
Alat pengembangan yang digunakan adalah dengan menggunakan $U M L$ diantaranya Use case dan activity diagram.

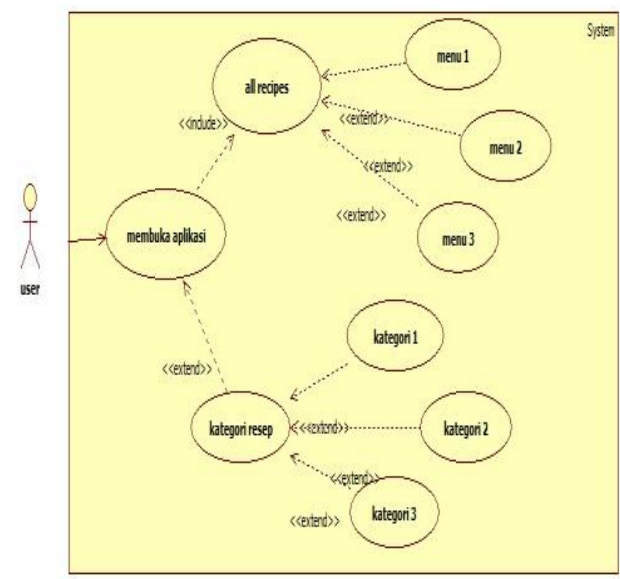

Gambar 2 Use Case Diagram User

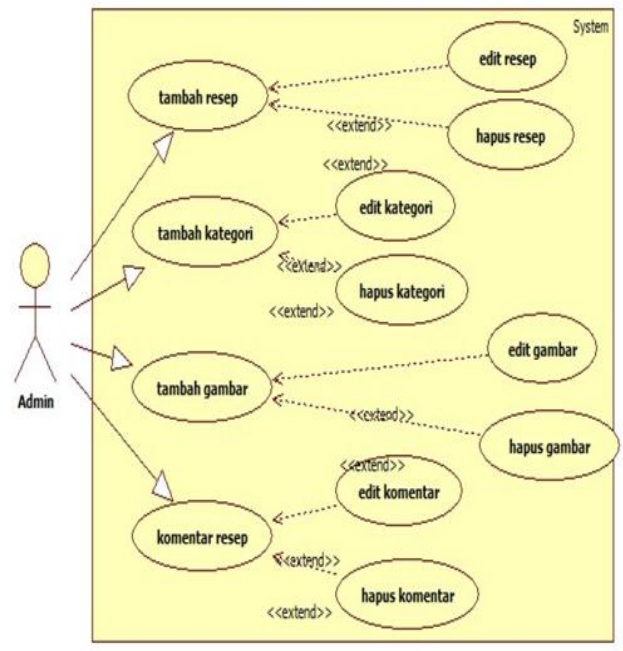

Gambar 3 Use Case Diagram Admin.

\section{Activity Diagram}

Activity diagram menggambarkan berbagai alir aktivitas dalam sistem yang sedang dirancang, bagaimana masing-masing alir berawal, decision yang mungkin terjadi, dan bagaimana mereka berakhir.

Berikut adalah Activity Diagram yang terdapat pada aplikasi resep masakan :

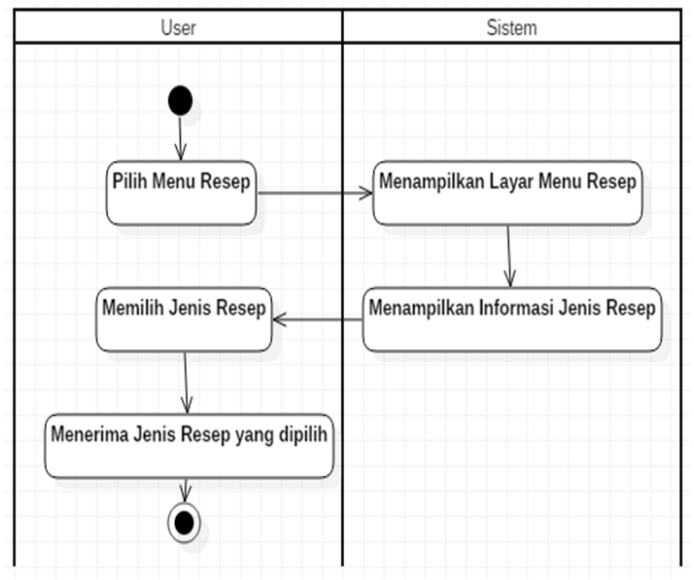

Gambar 4 Activity Diagram Menu Resep Masakan

\section{Sequence Diagram}

Sequence Diagram menggambarkan interaksi antar objek di dalam dan disekitar sistem (termasuk user, display, dan sebagainya). Sequence Diagram terdiri atas dimensi vertical (waktu) dan dimensi horizontal (objek-objek yang terkait).

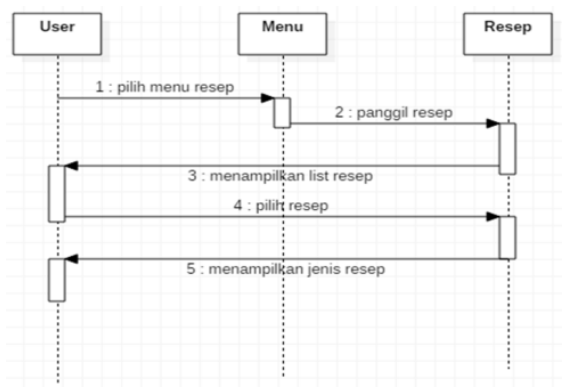

Gambar 5 Sequence Diagram Menu Resep Masakan 


\section{HASIL DAN PEMBAHASAN}

\subsection{Perangkat Keras (hardware) Yang Dibutuhkan}

Dalam mengimplementasikan sistem baru yang diusulkan spesifikasi program yang membutuhkan beberapa perangkat keras (hardware) yaitu:

1. PC/Laptop

2. RAM : 2 GB

3. Harddisk Internal 500 GB

4. Input Device : Keyboard, Mouse, Jaringan Internet

5. Output Device : Printer

\subsection{Hasil Program Dan Pembahasan}

Pada struktur menu Aplikasi Resep Masakan Berbasis Android memiliki 9 menu utama diantaranya Tampilan Utama Aplikasi, Halaman Detail Resep, Tampilan Login Admin, Halaman Dashbord, Halaman Posting, Halaman All Post, Halaman Categories, Halaman Comments, Dan Halaman User.

adapun tampilannya adalah sebagai berikut:

1. Menu Utama

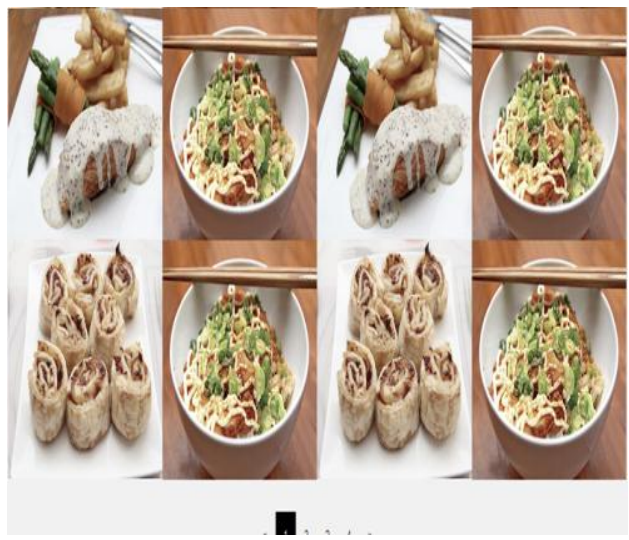

Gambar 6 Tampilan Utama Aplikasi Resep Masakan Berbasis Android

\section{Halaman Detail Resep}

Pada tampilan detail resep aplikasi menampilkan detail resep yang user pilih terdiri dari foto, nama resep, keterangan, bahan dan cara memasak, dan tombol kembali ke menu utama.

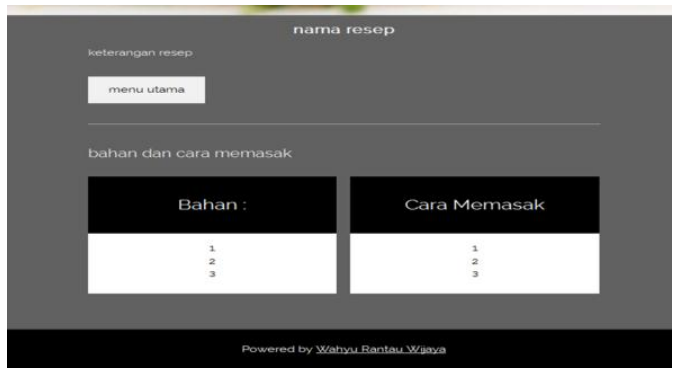

Gambar 7 Tampilan detail resep Pada Aplikasi Resep Masakan Berbasis Android

\section{Tampilan Login Admin}

Pada tampilan login admin ini adalah tampilan utama saat admin mengakses alamat web dan akan login ke sistem terdiri dari username dan password untuk login.

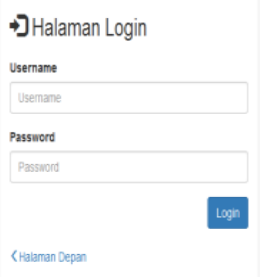

Gambar 8 Tampilan login admin Pada Aplikasi Resep Masakan Berbasis Android.

\section{Tampilan Halaman Dahsbord Admin}

Pada tampilan dashbord admin ini adalah tampilan utama setelah admin login ke sistem. 


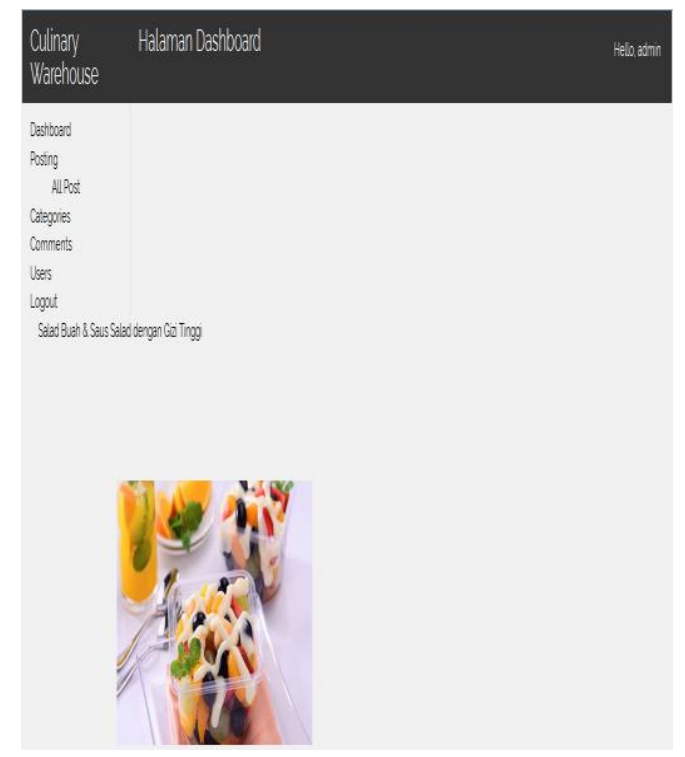

Gambar 9 Tampilan dashbord Pada Aplikasi Resep Masakan Berbasis Android

\section{Tampilan Posting Admin}

Pada tampilan posting aplikasi menampilkan form untuk posting resep artikel dan gambar.

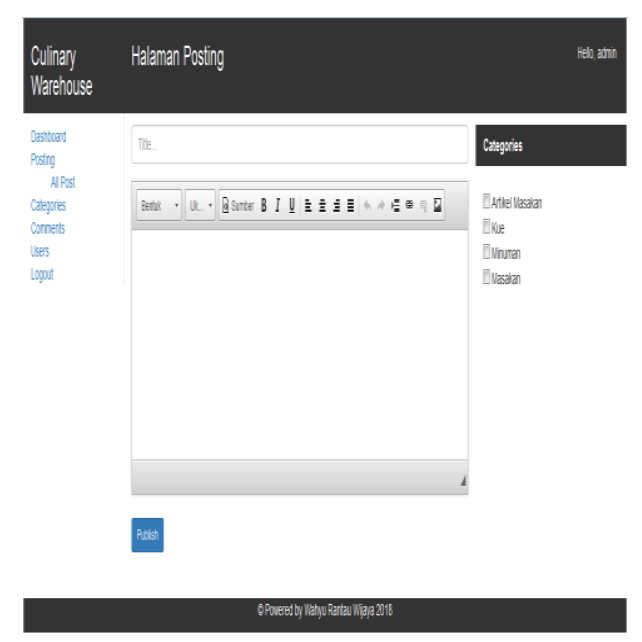

Gambar 10 Tampilan Halaman Posting Pada Aplikasi Resep Masakan Berbasis Android

\section{Tampilan All Post Admin}

Pada tampilan all post admin aplikasi menampilkan daftar artikel dan resep yang telah di posting admin.

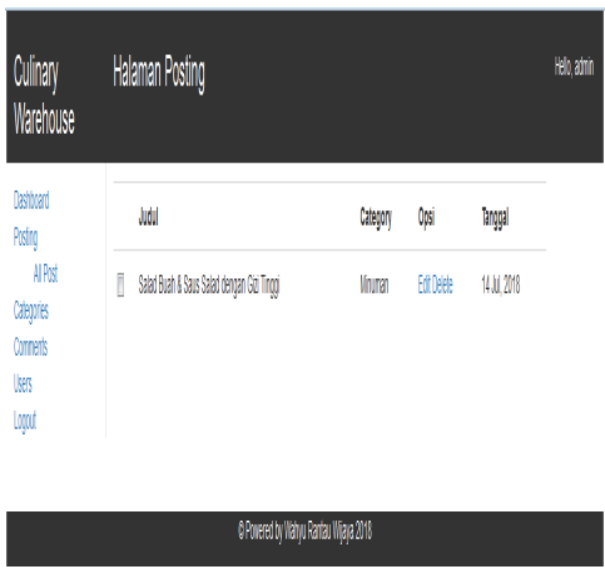

Gambar 11 Tampilan All Posting Pada Aplikasi Resep Masakan Berbasis Android.

\section{Tampilan Categories Admin}

Pada tampilan categories ini aplikasi menampilkan list kategori resep dan artikel yang akan di input admin.

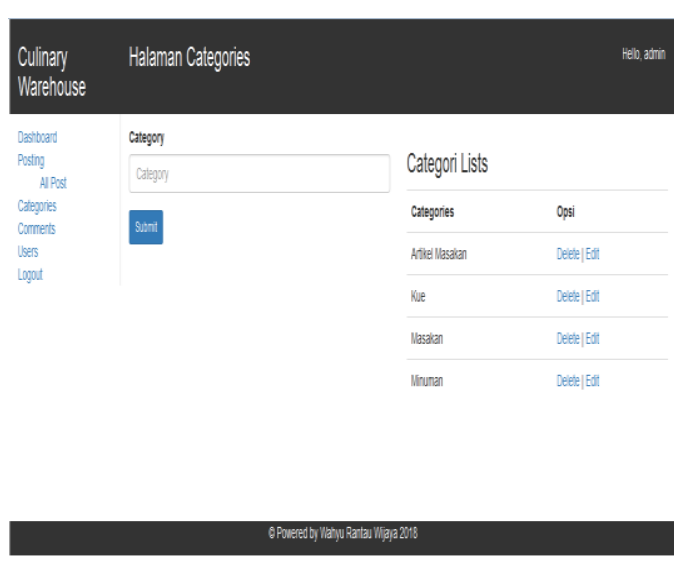

Gambar 12 Tampilan Categories Resep Pada Aplikasi Resep Masakan Berbasis Android.

\section{Tampilan Comments Admin}

Pada tampilan comments ini aplikasi menampilkan isi komentar dari user . 

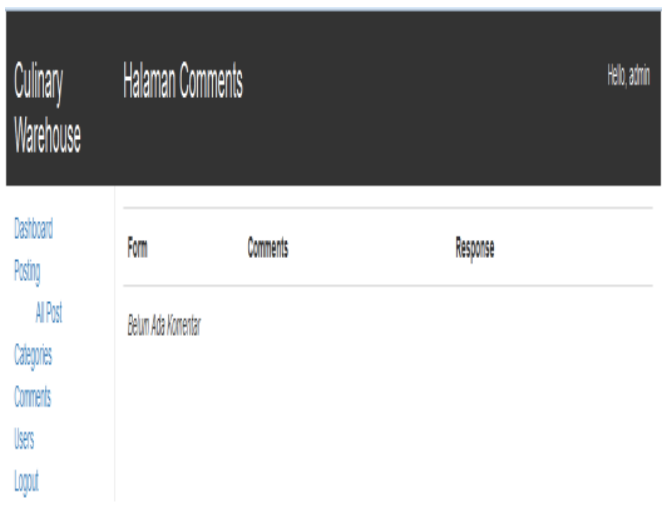

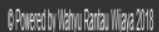

Gambar 13 Tampilan Comments Resep Pada Aplikasi Resep Masakan Berbasis Android.

\section{Tampilan Users}

Pada tampilan user ini aplikasi manampilkan list user yang telah ditambahkan oleh admin sebagai penulis atau administrator aplikasi resep.

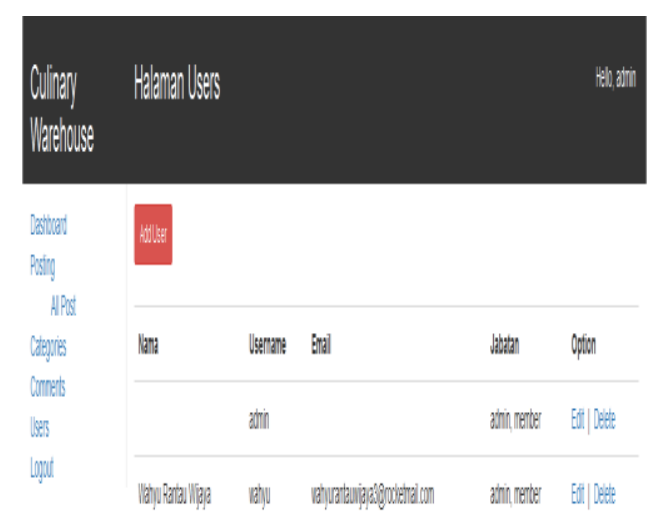

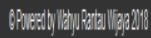

Gambar 14 Tampilan Users Pada Aplikasi Resep Masakan Berbasis Android.

\section{KESIMPULAN}

Sistem ini dapat menginformasikan kepada User tentang pencarian resep.Sistem ini dapat memberikan kemudahan dalam pencarian resep secara mobile tanpa harus terhubung dengan internet. Dan diharapkan dapat membantu User dalam kegiatan memasak.

\section{UCAPAN TERIMA KASIH}

Terimaksih kepada STMIK DCC Kotabumi beserta Tim Pengelola Jurnal INFORMASI DAN KOMPUTER, karena telah membantu dalam hal publiaksi dalam menulis penelitian ini.

\section{DAFTAR PUSTAKA}

[1] Ardhy, Ferly. "Sistem Informasi Monitoring Dan Pelaporan Dana Bos Berbasis Website Studi Kasus: Dinas Pendidikan Provinsi Lampung."

[2] Efendi, Dwi Marisa. "Sistem Informasi Geografis Rancangan Peta Digital Rute Angkutan Umum Kota Bandar Lampung." Jurnal Informasi Dan Komputer 5.1 (2017).

[3] Kahar, Novhirtamely, and Reny Wahyuning Astutui. "Aplikasi Pemesanan Makanan Online Berbasis Web Pada Rumah Makan Pagi Sore Sipin Jambi." Jurnal Informatika 7.2 (2013): 792-801..

[4] Efendi, Dwi Marisa, Muhammad Bayu, And Joni Darsyah. "Sistem Informasi Geografis Lokasi Kos Dan Penginapan Berbasis Web Pada Wilayah Kotabumi Kabupaten Lampung Utara." Jurnal Informasi Dan Komputer 6.2 (2018): 1-10. 
[5] Efendi, Dwi Marisa, and Ferly Ardhy. "Penerapan Data Mining Untuk Peramalan Penjualan Obat dengan Menggunakan Single Exponential Smoothing di Apotek Hamzah Farma." Prosiding Seminar Nasional Darmajaya. Vol. 1. No. 1. 2018. 